\title{
Making Education Equitable in Rural China through Distance Learning
}

\author{
Shiling McQuaide \\ Athabasca University, Canada
}

\begin{abstract}
The Distance Education Project for Rural Schools (DEPRS) was implemented by the Chinese government between 2003 and 2007 to improve the quality of basic education in rural areas of China, especially in the poorer western provinces. It has been referred to as "the largest ICT project in the world up to now" because "it serves a larger population than any other similar projects and therefore will likely start a far-reaching information revolution in China.” This paper offers a descriptive analysis of the effectiveness and impact of DEPRS, explaining how and why it was implemented as a solution to close the wide gaps in access to high quality basic education. Focusing on the initial achievements of DEPRS, this paper explores if, how, and to what extent the three learning tools employed in DEPRS have improved basic education in remote rural areas.
\end{abstract}

Keywords: three delivery models; Audio/Visual tools; DEPRS; ICT facilitated distance learning

\section{Introduction}

China has made great strides towards universalizing basic education in rural areas over the past two decades. Yet wide disparities in access to quality education continue to plague these areas. When the Hu-Wen regime came to power in 2003, it issued a development strategy that laid emphasis on the less developed inland provinces. Among the various programs and projects that the administration initiated to promote rural development, the Distance Education Project for Rural Schools (DEPRS) was a significant component. It aimed to improve the quality of basic education in rural areas of China, especially in the poorer western provinces. By early 2007, the bulk of the project had been successfully completed.

Distance education has been viewed internationally as a viable option for improving access to, and the equity and quality of, basic education in rural settings. A large body of literature has discussed different types of distance learning strategies and the contribution distance education has made to closing socio-economic gaps between developing and developed regions. Hilary Perraton states that distance education is a way to educate students who would otherwise get no 
education, and it is a tool to support and supplement conventional education in developing countries. Others highlight the important role distance learning plays in teacher training (Perraton, 2000, pp. 31-41; Moon \& Robinson, 2003; Graig \& Perraton 2003; Siaciwena \& Lubinda, 2008; Bof, 2004).

Some scholars, however, have questioned the merits of applying advanced information communication technology (ICT) in developing countries where children and adults lack even the most basic living standards. Shalni Gulati, for example, suggests that when developing countries implemented ICT-facilitated education projects, the efforts aimed at extending educational opportunities to disadvantaged and poor populations ironically often widened the socio-economic gap. In these countries traditional technologies, such as print media, radio, and television, remain more effective because the high cost of Internet service prevents poor people from accessing it (Gulati, 2008, pp.11-12).

A number of successful distance learning programs around the world seem to support Gulati's conclusion. In a study of India's National Open School, the most comprehensive distance learning program in the country to offer secondary education to learners from low income and disadvantaged social groups, K. Sujatha describes the school's delivery model as "combining self-study and Study Center support, complementing these with electronic media in a very limited way.” (Sujatha, 2002, pp. 95-96). Similarly, Telesecundaria, created in Mexico in 1968 to respond to the needs of remote villages, is a distance education program that uses television to carry most of the teaching load. In 1998, Telesecundaria's enrollment accounted for $17.6 \%$ of the country's total enrollment in grades seven to nine. Although people complain about the rigid scheduling of television broadcasting, full Internet connectivity is still considered technically difficult and too expensive (Wolff, Castro, Navarro \& Garcia, pp. 145,149).

In contrast to the above arguments, several researchers have highlighted the successful implementation of advanced ICT to promote rural economy and basic education in developing countries. Rabbi and Arefin, for instance, optimistically claim that wireless ad hoc networking will provide e-learning for rural people in developing countries and facilitate various educational services, such as Web-based learning, computer-based learning, visual classrooms, and digital collaboration, which are hard to obtain in underdeveloped areas (Rabbi \& Arefin, 2006). Bernadette Robinson, a distance education expert involved in the EU-China Gansu Basic Education Project, emphasizes the significant role advanced ICT played in teachers' training in Gansu Province. The project set up 686 Teachers' Learning Resources Centers, of which “85\% could connect to the Internet one way or another" (Robinson, 2008, p.3). Another case study focuses on Gansu, one of the most isolated, mountainous, and impoverished provinces in China. This study demonstrated that local communities benefited tremendously from ICT projects that were carried out to diffuse Internet technology in two rural counties (Zhao, Hao, and Banerjee, 2006).

By 2005, China was boasting the world's second largest Internet population with 103 million users. Rural users, however, still accounted for a mere $1.2 \%$ of the total (Zhao, Hao, and Banerjee, 2006, p. 294). ${ }^{\mathrm{i}}$ Chinese educators regard DEPRS as "the largest ICT project in the 
world up to now" since "it serves a larger population than any other similar project, and therefore will likely start a far-reaching information revolution in China” (Yu \& Wang, 2006, p. 276). With rare exceptions, however, the English-speaking world has paid little attention to the project (Yu \& Wang, 2006; Baggaley \& Belawati, 2007, pp. 40, 44). This paper offers a descriptive analysis of the implementation and impact of DEPRS and addresses questions that developing countries commonly face. The first section discusses the main factors that impeded the spread of basic education in rural China during the reform years (circa 1978 to the beginning of the twentyfirst century). The second section explains how and why DEPRS was implemented as a solution to enhance the quality of rural basic education. The third section focuses on the initial achievements of DEPRS, exploring appropriate and effective distance learning technologies that have been employed in rural China. And the fourth section deals with the challenges and problems that DEPRS faces. The conclusion sheds light on the effectiveness of ICT-facilitated distance learning tools in rural areas of developing countries.

\section{Main Factors Restricting Basic Education in the Rural West}

Compared to the eastern coastal regions of China, most parts of the western interior are underdeveloped. National statistical data published in 2000 showed that of 592 counties under the poverty line, more than half were located in the west (Sun \& Zhao, 2004, pp.111-2). In addition to having lower incomes, people in the rural west have had far less access to education, including basic education. A survey conducted in 1999 showed that illiteracy rates among the fifteen years and older age cohort in the western interior ran as high as $35.79 \%$, $14 \%$ higher than the national average (R. Wang, 2004, p.105).

One of the most crucial factors hindering the development of basic education in rural areas is the lack of qualified teachers. During the reform years, when the government lifted the regulation and control over labor mobility, a large number of experienced teachers left the poorer regions or the countryside for developed areas and urban centers. In 2001, there were 705,000 primary and secondary school daike teachers (teachers who are not on the government payroll, but who are locally appointed and funded) nationwide, accounting for $6.6 \%$ of the total teaching staff. They were concentrated in the rural areas of western China. In Guangxi Zhuang Autonomous Region, Tibetan Autonomous Region, and Shaanxi Province, daike teachers accounted for $20 \%$ of the primary and secondary school teaching staff. Many of them were not well-trained (Zhuang \& Lai, 2002, p. 26). In the urban centers in Eastern China, $44.4 \%$ of primary school teachers had a college diploma or university degree. By contrast, only $15.6 \%$ of those in the rural west had equivalent credentials (J. Zhao, 2005, p. 3; T. Wang, 2004, p.64).

The shortage of teachers compounded another problem, that of a shortage of teachers who could teach in special subject areas. Conventional subjects such as Chinese literature have not been problematic, but there has been a growing shortage of people who can teach in modern subjects, such as English, computer science, music and physical education. As a result, some courses listed in rural curriculums are no longer offered, while other subjects are taught by teachers trained in different disciplines. It is commonplace to find teachers in western rural schools 
teaching subjects in which they have no training or expertise (J. Zhao, 2005, pp. 4-5; Wu \& Yang, 2005, p. 12).

Another problem hindering the spread of basic education in western rural China is the shortage of funding. A large percentage of the rural population lives below the poverty line and there is not enough economic development to support local education. Under the new reforms, the administration initiated a fiscal policy which translates as "eating from separate pots." Unfortunately, this policy has significantly reduced the transfer of resources from rich areas to poor ones. As a result, the inequity in public spending has increased dramatically. To cite but one example, in the early 1990s, Shanghai, the most developed coastal metropolitan city in eastern China, spent about five times more than the poorest rural area on primary education. One decade later Shanghai spent ten times more than the poorest rural area (Hannum \& Park, 2002, p. 9).

The lack of funding also had a negative impact on teachers' working and living conditions. Because of heavy workloads, tight budgets, and poor transportation, rural teachers had little opportunity to attend training sessions, to undertake research activities, or to observe exemplary teachers using innovative methods in the classroom. Funding shortfalls also meant that the income of rural school teachers was much lower than that of their city counterparts. In addition to lower wages, most rural teachers do not have guaranteed medical insurance, pension plans, or social security. The teachers employed in village primary schools are not entitled to any benefits (J. Zhao, 2005, p. 5). In spite of the media regularly advocating teaching as a "glorious" career, few graduates are willing to work in the countryside for lower wages and even lower social status (Zhang, 2003, p. 118).

\section{Enhancing the Quality of Rural Basic Education through Distance Learning}

For current Chinese leaders, universalizing basic education in rural China has been viewed as a way "to help narrow the social gap and to realize social justice." They emphasize the key role basic education plays "in alleviating social conflicts and constructing a harmonious society" (Wen, 2003; Chen, 2005, p. 3). Since the turn of the $21^{\text {st }}$ century the government has instituted a number of education projects in rural China under the broad rubric of developing the underdeveloped western hinterlands. Distance learning tools have played a significant part in this goal (Yang \& Yuan, 2006, p. 24; H. Zhao, 2005, pp. 3-10). ${ }^{\text {ii }}$

Drawing upon the success of other countries, Chinese educators have argued forcefully that China needs to develop distance education because it is adaptable, cost effective, diverse, and open (Zhang, 2002, p.102; Liang \& Li, 2005, p.11). Ding Xingfu, one of the leading scholars in distance education, has convincingly argued that "Distance education is the only means by which high quality education resources can be conveyed from the eastern part to the western part. It is also the only means by which qualified teachers can be cultivated and retained in the West" (Ding, 2003, p.13). 
In September, 2003, the State Council issued the ground-breaking document Decision on Further Strengthening Rural Education. It explicitly stated that the government was to "implement the distance education program in rural schools for the purpose of promoting educational resource exchanges between urban centers and rural areas and to enhance the quality and effectiveness of education in the countryside." Central and local governments committed twelve billion RMB Yuan to the program (Ding, 2005; Liu \& Sun, 2006, p. 39). ${ }^{\text {iii }}$ Between 2003 and 2004, the Ministry of Education, the National Committee of Development and Reform, and the Ministry of Finance worked together and launched two experimental programs in distance education. Based on the successful results of the two pilot programs, the State Council approved the general scheme of constructing a nationwide rural distance education network, known as DEPRS, in 2004. The DEPRS proposed to develop and install three delivery models to suit various levels of instruction in rural schools within five years.

The first of the three distance delivery models targeted the 110,000 low level rural elementary schools located in sparsely populated natural villages or administrative villages. This type of small school normally serves grades one through three, with between 10 and 20 students in each grade. The school hires up to four teachers, who are likely to teach different grades in rotation. This model uses Digital Video Disc (DVD) technology to facilitate learning. Each school is equipped with a set of DVDs, a DVD player, and a television (TV) set. The DVDs contain lessons given by nationally recognized teachers who specialize in language, mathematics, and other subjects. The discs function as teaching and training tools for teachers and students alike. The cost of a complete setup, including equipment, is estimated at 3,000 RMB Yuan. To support this delivery model, the Ministry of Education solicited the public for contributions. The Ministry also viewed a large body of teaching materials for use in the production of the DVD programs (Zibo, 2005; Miao, 2005; Wang, 2005; Yu, 2005; Lee and Wang, 2005).

The second distance delivery model has been designed to meet the needs of the 384,000 intermediate schools (grades one through six) located in townships or large administrative villages. This model contains the same material and equipment as the first model but also provides for advanced satellite technology for televised broadcasts. The DVDs contain teaching materials for grades one through six. The satellite dish receives education programs produced by central and local television stations. The estimated budget for this model is about 16,000 RMB Yuan.

The third model is aimed at serving some 37,500 rural junior high schools. The most advanced and costly of the DEPRS models, the third model contains provisions for computer rooms equipped with high-speed Internet and multimedia classrooms. It also provides a satellite television, a DVD player, and a set of DVDs. In addition to playing DVDs and showing television education programs, the third model allows teachers and students to download online and Web-based materials. The cost for setting up this model is as high as 150,000 RMB Yuan (J. Zhao, 2005, p. 7; Guo \& Guo, 2006, p. 62). To support the second and third models, the education channel of Chinese Central Television airs an eleven hour long program titled Air Classroom on a daily basis. Several Web-based educational programs are provided by the Ministry of Education, including Classroom for Primary \& Secondary Students and Teacher's 
Training. The Central Bureau of Audio-Visual Education supplies teaching resources for rural schools through radio broadcasts. Regional education administration authorities have been engaged in research and development to produce teaching materials that address the specific needs of rural students. Regional officials regulate the delivery models but they also offer comprehensive guidance (J. Zhao, 2005, p. 2).

\section{Application of Delivery Models to Primary \& Secondary Education: Initial Accomplishments}

By early 2007, official reports were declaring that in most provinces the bulk of the installation work on the three models had been completed or nearly completed. At the DEPRS Work Report Conference called in 2007, Li Tianshun, head of the Basic Education Bureau of the Chinese Education Ministry, claimed that "enormous progress has been made." According to Li, "a total of 8 billion [RMB Yuan] have been spent on the project; the three models have been implemented in over $80 \%$ of the primary and secondary rural schools in central and western China, which allows more than 100 million rural school children access to high quality educational resources” (T. Li, 2007). By the time all three delivery models have been fully implemented, some 118 million rural primary and secondary students will have benefited from the program (Liu \& Sun, 2006, p. 38).

At times government officials and media in China appeared to be obsessed with the success of the delivery models themselves. It is critical for policy makers and administrators to realize that building the physical infrastructure is only the first step of DEPRS. The next serious challenge is how to make full use of modern distance learning technologies, integrating high quality teaching materials with local classroom instruction and updating rural teachers' pedagogy (Baggaley \& Belawati, 2007, p. 44; Yu \& Wang, 2006, pp. 277-279). The urgent task is to assess the beneficial results and analyze the cost effectiveness of DEPRS in order to ensure the sustainable development of the project.

According to experts in distance education, when distance learning methods are applied to basic primary and secondary education "where educational technology has been used to enhance education rather than to provide an alternative, its costs are additional to those of regular schools. If these technologies are to be used, they need to demonstrate an educational value that justifies the extra cost." (Perraton, 2000, pp.127-8) In line with such thinking, national counsellor Chen Zhili has contended that the added benefits must be the critical criterion for assessing the project, which can be demonstrated by teaching and learning improvements in rural basic education (Yang \& Han, 2007, p. 20).

This discussion of the beneficial results of the DEPRS program is based on two categories of investigation - overall regional evaluations based on statistic data and case studies that examine the effectiveness of the different delivery models, supported by concrete examples.

\section{The Impact of DEPRS on Rural School Performance}


Although the evaluations under discussion looked at the three categories of schools, teachers, and students, this paper specifically focuses on student development. Teachers' quality admittedly plays a key role in rural education, but the eventual goal of distance education projects are improvements in student performance. In addition, one of the case studies in the next section pays special attention to teachers.

Two evaluations were conducted by university and school educators to assess the project's impact on various aspects of rural education in 2006. One covered thirteen provinces, with an emphasis on five provinces and one municipal city (Gansu, Ningxia, Qinghai, Shaanxi, Sichuan and Chongqing City). The other focused specifically on Gansu province. In addition to questionnaires and classroom observation, in-depth face-to-face interviews were conducted. Thirteen directors of the Bureau for Education with Electrical Audio/Visual Aids, 346 school principals, 2,876 teachers, and 465 equipment maintenance technicians were involved in the thirteen province survey. In the Gansu survey, one director of the Bureau for Education with Electrical Audio/Visual Aids, 86 school principals, 159 equipment maintenance technicians, and 567 teachers were interviewed (Yang, Sun and Ding, 2007, pp. 97-98; Yang \& Han, 2007, pp. 20-21).

Although the two research teams conducted the evaluations using identical methods, concentrating on the same areas, and asking similar questions, the results were quite different.

\section{Table 1}

\section{Fostering Student Development: Gansu Province}

\begin{tabular}{l|c} 
Targets & \% of Agreed Participants \\
\hline Inspiring interests in study & $94.4 \%$ \\
\hline Improving understanding of subject matters & $75.8 \%$ \\
\hline Promoting independent thinking & $72.4 \%$ \\
\hline Stimulating imagination & $67.1 \%$ \\
\hline Cultivating creativity & $72.6 \%$ \\
\hline Cultivating hands-on ability & $64.9 \%$ \\
\hline Improving ability in information collection & $63.4 \%$ \\
\hline Broadening intellectual horizon & $89.3 \%$ \\
\hline Enhancing overall study ability & $70.7 \%$
\end{tabular}

(Yang, Sun \& Ding, 2007, p. 98) 
Table 2

Fostering Student Development: 13 Provinces

\begin{tabular}{l|c} 
Targets & \% of Agreed Participants \\
\hline Stimulating interests in study & $53.08 \%$ \\
\hline Increase effectiveness of study & $11.54 \%$ \\
\hline Promoting critical thinking & $18.68 \%$ \\
\hline Cultivating creativity & $12.20 \%$ \\
\hline Cultivating hands-on ability & $8.21 \%$ \\
\hline Improving ability in information collection & $14.09 \%$ \\
\hline Broadening intellectual horizon & $59.45 \%$ \\
\hline Inspiring imagination & $28.24 \%$ \\
\hline Promoting ideology and morality & $6.26 \%$
\end{tabular}

(Yang \& Han, 2007, p. 21)

As the two tables show, in almost every aspect the thirteen provinces consistently scored much lower than Gansu. The more positive results displayed in the Gansu survey were likely due to the fact that Gansu is one of the least developed provinces in western China and a number of projects in addition to DEPRS have been implemented in the past decade to help improve rural education. ${ }^{\text {iv }}$

Regardless of the differences, both surveys displayed a similar pattern with respect to the effectiveness of the project, that is, the highest effectiveness remains at the superficial level. Achievements are most pronounced in areas that are readily affected by the audio/visual technology in the three DEPRS delivery models because they provided students with access to a large variety of learning materials via DVDs, satellite television and Web/Internet supported ICT. For example, when asked if DEPRS had stimulated student interest in studying and widening their intellectual horizons, a very large number of informants responded positively $(90 \%$ in the Gansu survey and about 55\% in the thirteen provinces survey); but when asked if the project had improved students' creativity, enhanced their critical thinking skills, and promoted their hands-on ability, a much smaller number of respondents reacted positively (72.6\%, $72.4 \%$ and $65 \%$ in the Gansu survey; $12.2 \%, 18.7 \%$, and $8.2 \%$ in the thirteen province survey).

This discrepancy demonstrates that the full potential of distance education technologies has not been realized. Teachers and scholars in China are engaged in discussions on how to transfer conventional classrooms based on chalk and talk to a new learning environment that is reliant on distance learning materials. They emphasize the promotion of student self-motivation for learning and the transformation of students from passive learners driven by exam scores into active and well-disciplined learners, who take the initiative in creative learning and critical thinking. In addition, responding to a common weakness of Chinese basic education, that of neglecting the development of practical skills in students, they call for appropriate teaching methods to enhance students' hands-on ability (Ou, 2008, 191; Liu \& Zhang, 2008, pp, 7-8). The two investigations show that the new pedagogy has not prevailed in the vast western rural 
regions. There is, unfortunately, no statistical data available on student examination pass rates to make a solid and objective evaluation of the academic performance of rural students.

\section{Promotion of Rural Education through Three Delivery Models: Case Studies}

This section will focus on two case studies. The first, undertaken in Hubei Province, involved the implementation of the first and second DEPRS models in rural primary schools to provide instruction in English language skills. The second case study entailed the use of the third DEPRS model in a junior high school in Gansu Province to improve the professional development of teachers.

\section{Hubei Case.}

Hubei Province is located in central China. In 2002, the Provincial Education Bureau, following a resolution issued by the central government, decided to offer English language courses to all primary school pupils starting in the third grade. The target date for the commencement of the project was 2005. The decision presented rural schools with a serious challenge because qualified English teachers and teaching resources were scarce.

There are 16,000 primary and intermediate schools in the rural regions of Hubei but just one thousand formally trained English teachers. The overwhelming majority of rural schools could not offer English language instruction because they simply had no teaching staff. In addition to that problem, most rural primary English teachers only have a modicum of training, the result of which is poor pronunciation and a limited grasp of grammar and vocabulary. Most rural teachers tend to teach more than one subject, which further works against attaining proficiency in English. In addition, tight budgets do not allow most schools to purchase necessary teaching resources and equipment. Teachers therefore have had to rely on textbooks and a handful of audio tapes. There were no language labs or library materials that would help students to improve proficiency in English through listening, speaking, and reading. Rural schools faced the almost impossible task of finding enough qualified teachers and teaching and learning resources within three years to meet the deadline of 2005. (Fang \& Shao, 2007, pp. 34-35).

Two options were proposed. The first was to recruit a massive number of English teachers from college graduating classes and to assign one to every rural primary school. The second was to utilize the distance education infrastructure in DEPRS and to develop English instruction through the provincial TV education channel and DVD broadcast stations. These distance learning sources could then be used to either supplement English instruction in those schools where English teachers were not particularly well trained or as an instructional substitute in the schools where no English teachers were available. The first option was quickly rejected because Hubei Province lacked the financial resources to hire English language graduates, and without salary incentives few qualified English teachers would move to a rural setting. Even those who chose to work in rural areas for personal reasons tended to return to urban life after a short period of time. ${ }^{\mathrm{v}}$ 
The second option proved to be more attractive because it was cost effective and flexible. The first and second DEPRS delivery models were scheduled for completion in 2005, thereby providing the necessary ICT equipment for distance education in English (Fang \& Shao, 2007, p. 35). ${ }^{\mathrm{vi}}$

A course development group, composed of one British expert and four highly experienced Chinese educators in early English education, was formed to produce a distance education course for grades three through six. The course, Elementary School Air Classroom in English, was produced as a TV program and a set of 160 DVDs, each of which contained two English lessons. Every rural elementary school received one set of the DVDs at the beginning of the fall semester in 2005. In the meantime the Provincial Bureau for Education with Electrical Audio/Visual Aids organized training sessions for rural English teachers, helping them to implement the distance teaching materials into their classroom instruction. About 1,400 trainees became part of a core group who promoted distance English education in their school districts. The Provincial Bureau for Education with Electrical Visual/Audio Aids also sent trainers to each county to offer training classes. Some 13,200 rural teachers underwent training and almost every elementary school now has a teacher who attended the training sessions (China Education Paper, August 17, 2008).

Between 2005 and 2007, all rural elementary schools offered English language instruction with the aid of TV and DVD broadcasting. At the remote elementary schools (grades one through three), an effective teaching model was designed to help teachers who know little English to undertake instruction. Part of the training involved teachers repeatedly viewing the DVD programs before the class. During class instruction the teacher would play a given DVD program, stopping and repeating sections of a given lesson whenever students could not follow. Students who developed proficiency participated in class instruction, helping to demonstrate the proper pronunciation of various English words and phrases. In the intermediate schools where English teachers underwent training but did not have a sure grasp of the subject material, the TV courses helped them to improve their teaching methods and to keep abreast of new teaching innovations.

A comprehensive evaluation of Elementary School Air Classroom in English undertaken in 2007 by a team of experts from the Provincial Bureau of Education, the Provincial Bureau for Education with Electrical Audio/Visual Aids, and the Education Research Center of Hubei Province revealed that it was quite effective as a teaching model. The team was convinced that the use of TV and DVD technology was successful at transferring advanced teaching resources from urban centers to remote rural regions, allowing teachers with little formal language training to fulfill their task. Four million rural children were subsequently able to enrol in English classes, which otherwise would not have been available to them. There is also clear evidence of student improvement in pronunciation and conversational ability. A Provincial Speech Contest of Rural School Pupils was held in Wuhan, the capital city of Hubei Province, in August, 2008. The audience and the judges were deeply impressed by the English fluency of the village children. After watching the video tape of the speech contest and inspecting several schools, government officials and experts, including the Minister and Vice Minister of Education in China, spoke 
highly of the TV course as "the best solution to the teacher shortage in rural areas." (Fang \& Shao, 2007, p. 37; China Education Paper, August 17, 2008; Hubei Bureau, 2007).

\section{Dangzhai middle school case.}

Dangzhai Middle School is a rural junior high school under the jurisdiction of Zhangye Prefecture in Gansu Province. Zhangye became one of the pilot counties for the implementation of DEPRS in 2004 with 626 primary and secondary schools in the prefecture receiving one or more of the three distance delivery models. Despite the cost of the installation of the ICT equipment, especially for the third model, by 2007 many teachers were complaining about the amount of time they had to spend on class preparation for the new multimedia technology. Owing to an already heavy workload, many teachers continued to use conventional teaching methods. Only occasionally did they integrate multimedia material with classroom instruction and then it was usually when school inspectors stopped by for classroom observation (Peng, 2007, p. 3; Zhang \& Shi, 2008, p. 78).

Nonetheless, unlike many other middle schools, Dangzhai, an ordinary rural school with 1,300 students and teachers, made significant progress in incorporating the third DEPRS model into classroom instruction, in pedagogical innovation, and in community service. A multimedia classroom equipped with thirty computers and broadband Internet was set up as well as a classroom equipped with an overhead projector. The school was also supplied with satellite televisions and DVD players.

The school administration was fully cognizant of the fact that training would be the key to the successful application of the distance delivery models. So once the hardware was installed, the school offered general training sessions to help teachers become computer literate and more effective at researching and utilizing Internet sources; this included the ability to use general software, such as Word, PowerPoint, Excel, Flash, and programs specifically designed for certain subjects, such as www.GspInChina.com for math, Simulated Physics Lab for physics, Golden Mountain Graphic King for fine arts, and other applications. Specific training sessions were held to help teachers develop a basic knowledge in designing and utilizing multimedia material in the classroom. To ensure that every teacher obtained the necessary computer skills, they were divided into a number of small groups in which the more advanced teachers would act as tutors. The groups would also solve various problems that others had encountered. Part of this process was aided by the fact that during the initial stages of the implementation of DEPRS the principle of sharing teaching material was heavily promoted in the belief that it would help reduce workloads. Capable teachers who had strong ICT skills were encouraged to play a key role in course development by helping to design multimedia classes in certain subject areas and by drafting courses that were peer reviewed. The final product was remarkable due to the extensive collaboration and sharing that occurred. School administrations have vowed to continue this sharing process until most teachers have become proficient in utilizing multimedia tools in the classroom (Peng, 2007, pp.14-16, 22-23). 
A survey conducted by Peng Su, a graduate student majoring in Education Management at Dangzhai Middle School, indicated positive attitudes towards the new technology. The survey covered six categories, ranging from overall knowledge, online resources, and teacher training and course development to professional development and community service. The majority of respondents supported the program, and 95\% of the teachers surveyed believe that the project is necessary. The majority of teachers and students indicated that rich learning resources were available at the school and that they were able to conveniently access those resources. A database storing distance leaning resources has been set up at the school under the care of a professional manager. Regulations on downloading, saving, and borrowing resources have been introduced to insure that teachers and students have easy access to resources.

Many teachers, however, still have only basic ICT computer skills (Word and PowerPoint). Although they were able to research, download, categorize, save, and display online sources relevant to their teaching, $38.2 \%$ of teachers lacked the ability to operate sophisticated software such as Authorware or Photoshop or to produce a workable multimedia course. Despite this, most teachers have improved their classroom performance through the use of enriched learning resources and they have begun to promote students' self-learning, active inquiry, and collaborative research. Some, though, lack the motive and the incentive to learn new educational theories and pedagogic innovations because mastering the newer approaches requires strong critical analytical skills and a substantial investment of time for results that will appear only gradually over time (Peng, 2007, pp. 32-33).

In comparison to the three other DEPRS model schools, where the expensive equipment has often become obsolete, Dangzhai has made remarkable progress in applying Internet-facilitated distance learning techniques to the classroom. Admitting that the key to educational reform is the teachers, school authorities issued policies, provided training sessions, and initiated strategies to encourage cooperation and sharing of teaching materials. Thus, the school has successfully promoted the development of computer technology amongst its teachers to the point where $96 \%$ of the Dangzhai teaching staff obtained a certificate of computer literacy from Zhangye Prefecture. The policy of sharing teaching materials has reduced the time spent on class preparation and hence the workload to the point where all teachers are now eager to employ multimedia materials in their classroom instruction. Furthermore, about $65 \%$ of teachers have the ability to use the distance learning technology to design and produce multimedia classes. In the spring of 2006, five Dangzhai school teachers attended a teaching contest hosted by Zhangye City, and all five teachers won an award. The news earned Dangzhai national fame and inspired other rural schools (Peng, 2007, pp. 38, 41). In July of the same year, National Counsellor Cheng Zhili and Minister of Education Zhou Ji inspected Dangzhai Middle School (Peng, 2007, p.4).

\section{Challenges and Tentative Solutions}

The DEPRS project faces many problems and challenges, some of which are described below. As well, tentative solutions are offered.

\section{Shortage of Funding}


Now that DEPRS is moving into the full implementation stage, funding will become a critical factor. The 12 billion RMB Yuan allocated for infrastructure accounted for less than 1/3 of the total cost of the project, and as international experiences demonstrate, more funds will be needed in order to insure that DEPRS remains sustainable. The central government, however, has stated that it will not accept responsibility for any more costs, so various levels of local government must explore and establish an effective mechanism to guarantee that the project operates properly. One further complication is that the governments are not allowed to levy additional taxes on peasants (Ding, 2005).

Of the rural schools that have the three delivery models installed, $84 \%$ are located in the economically underdeveloped west. If local governments are forced to shoulder the financial burden single-handedly, a fairly large number of the western counties will be unable to cover personnel, equipment maintenance, teaching materials, and operation costs. The thirteen provinces investigation indicates that in some schools, models two and three are not in use owing to high maintenance, Internet connection, and electricity costs. As well, many schools lament that they cannot pay for course materials and training sessions (Yang \& W. Jia, 2007, pp.48-49).

Facing the funding shortage, Chinese distance educators argue that the central government should share the cost for the implementation stage together with the local authorities. They contend that because DEPRS is designed to promote compulsory education, it is different from the corporateoriented, profit-driven distance education programs that prevail in urban centers. Compensation for DEPRS should reflect the mandate to promote compulsory education. The state, after all, is the biggest beneficiary of the project, though businesses, social organizations, and individuals benefited from it as well. All parties, therefore, should share the cost (Yang \& Sun, 2007, 57; Ding, 2005). Finally, a number of suggestions have been made to increase the cost effectiveness of DEPRS, such as launching inter-provincial collaborative partnerships on the development of course materials and offering in-school training sessions to reduce teachers' travel costs (Yang, Sun \& Ding, 2007, 97).

\section{Insufficient Learning Materials}

At this stage, the distance learning materials primarily consist of video recordings and TV programs of exemplary lectures delivered by experienced teachers, learning activities taking place in urban schools, and sample examination questions. These tools are invaluable considering the dearth of instructional materials and teachers in rural areas, but they may not be completely suited to the needs of village students, especially those of minority ethnic groups. Living conditions and lifestyles in urban and rural China are drastically different; minority groups have their own history, literature, culture, music and customs. An investigation conducted in fifteen schools scattered across three counties of Shaanxi Province revealed that $79 \%$ of teachers interviewed did not like the "canned" course materials they had to use. Instead they preferred flexible teaching resources that could be utilized in their teaching plans with minor revisions (Liu \& Zhang, 2008, p. 8; Yu \& Wang, 2006, pp.277, 280; F. Li, 2007, p.3). In Tibetan Autonomous Region, most materials used for the Tibetan language course in middle schools have been translated from the 
national textbook, which is comprised of literary works by well-known Han writers. The oftquoted and widely circulated Tibetan novels, lyric, rhymed verses, and love songs are barely mentioned (Liu, 2006, p.79).

Chinese scholars argue that the key for developing appropriate course materials for DEPRS lies in changes to the way courses are produced. Course content should be drawn from the experience and setting of the countryside, and experts and teachers from rural regions should be involved in designing courses. "The ‘top down' approach must give way to a 'grassroots' approach in which people in the rural areas are active participants rather than passive receivers of materials that were conceived for learners in other populations and contexts.” (Yu \& Wang, 2006, pp. 280-281; F. Li, 2007, p.3)

\section{Conclusion}

DEPRS, the distance learning project designed to transfer high quality education resources from urban centers to remote rural regions, was employed during the reform years as a crucial measure to counteract the rapidly growing class and regional disparity in basic education.

Although a full evaluation of the project is not yet available, partial but persuasive evidence points to several tentative conclusions about the effectiveness of DEPRS at the early stages of its implementation. First, this paper has argued that the project has had a visible impact on raising the quality of rural education by enriching learning resources and alleviating teacher shortages. Courses that were not offered in the past are now available to village children, something that is clearly demonstrated by the Hubei English Teaching Case. About $83 \%$ of rural school teachers in the western provinces have attended training programs. Almost all of them have agreed that "the training is very helpful or somewhat helpful to them" (Yang \& Han, 2007, p.20). Students have become more interested in learning and their intellectual horizon has been widened thanks to a variety of learning resources conveyed to them through the three delivery models.

Second, the results of the two surveys conducted in Gansu province and in the thirteen provinces demonstrate that when DEPRS has been used in conjunction with other programs it has been more effective in less prosperous regions, such as Gansu. Third, the two surveys also show that the impact of DEPRS remains superficial, and, except for a minority of rural schools, it has not substantially changed pedagogical approaches. It will take a longer period of time and further efforts for the project to produce the desired results. Moreover, the DEPRS delivery technology may have some inherent limitations. Model one and model two are the most extensively used distance learning tools. As one-way learning tools, they are less likely to stimulate vigorous interaction between teachers and students in comparison with the ICT-facilitated distance education technology.

In conclusion, Chinese distance educators and teachers largely support Shalni Gulati's observation, preferring the first and second DEPRS models as the most suitable distance learning technology in poor and remote western rural regions owing to their low cost and ease of operation (Ma \& Liang, 2008, p.9; Yang \& C. Jia, 2007, p.58; Zhang \& Shi, 2008, p.78; F. Li, 2007, p.3; 
Xie, 2007, p.50; Lee \& Wang, 2005, p.259). The more expensive third DEPRS model, with its sophisticated technology, is more likely to be neglected by teachers in underdeveloped rural areas. To increase the effectiveness and efficiency of the third model, the rural schools need to initiate innovative policies and invent viable strategies to encourage cooperation, mutual accommodation, and the sharing of teaching materials, as the experience of Dangzhai Middle School indicates.

The findings of this paper, together with the example of successful experiences in India and Mexico, have shown that in populous developing countries, low cost and conventional learning technologies continue to play a crucial role in distance education programs aimed at learners from socially and economically disadvantaged groups who have limited access to the Internet. Furthermore, when Internet-facilitated learning technology is introduced to rural areas in developing countries, authorities must formulate appropriate policies and offer financial subsidies to ensure the full application of the new technology. If not, the costly infrastructure may become obsolete in remote and poverty-stricken regions and the digital divide between the haves and the have-nots will grow. This is not to say that developing countries like China should concentrate on conventional learning tools. In order to be successful, rural education in China will have to rely on new technologies. However, as Shalni Gulati argues, the governments of developing countries need to respond to the serious challenges involved in implementing advanced ICT learning tools, and they must increase investment in underdeveloped regions as well as issue policies to enhance the cost effectiveness of such education technologies. 


\section{References}

Baggaley, J. \& Belawati, T. (Eds.) (2007). Distance education in Asia: I. Past and present. Lahore: VUP.

Bof, A. M. (2004). Distance learning for teacher training in Brazil. International Review of Research in Open and Distance Learning, 5(1), 1-14.

Chen, Z. (2005). Speech at the experience exchange conference on applying distance education models to rural primary and secondary schools in central and western China. Education of Information Technology, 4, 3-7.

China Education Paper, August 17, 2008.

Craig, H. \& Perraton, H. (2003). Open and distance education for teachers' continuing professional development. In B. Robinson \& C. Latchem (Eds.), Teacher Education through Open and Distance Learning (pp. 91-111). London: RoutledgeFalmer.

Ding, X. (2003). Developing the distance learning in rural primary \& secondary schools and facilitating the process of modernizing basic education. Distance Education in China, $17,13-17$.

Ding, X. (2005, May 16). We cannot neglect the analysis of the total cost. China Education Paper.

Fang, Z. \& Shao, Z. (2007). The exploration and practice of using DEPRS to promote English language teaching in the primary schools of Hubei province. Journal for Technical Education, 12, 34-37.

Gulati, S. (2008). Technology-enhanced learning in developing nations: a review. International Review of Research in Open and Distance Learning, 9(1), 1-16.

Guo, S. \& Guo, J. (2006). Rural distance education: applying distinct models to different situations. Information Technology Education for Primary \& Secondary Schools, 5, 6271.

Hannum, E. \& Park, A. F. (2002). Educating China's rural children in the 21st century. Harvard China Review, 3(2), 8-14.

Hubei Bureau for Education with Electrical Audio/Visual Aids. (2007). Newsletter, 4.

Lee, C. \& Wang, J. (2005). Using VCDs to promote rural educational development in China: A case study in the Tianshui hilly areas of Gansu. Open Learning, 20(3), 257-264.

Li, F. (2007). Using DEPRS to promote the rural education. New Education, 4, 3. 
Li, T. (2007, Nov. 27). Talk about the progress of DEPRS. Retrieved January, 2009, from http://www.thedu.gov.cn/taihe/moshi3/10515

Liang, J \& Li, F. (2005). Distance education: the most feasible means to promote equitable education in poverty stricken regions. Journal of Gansu Radio \& TV University, Page | 17 15(4), 10-13.

Liu, D. (2006). Inspirations of multi-cultural education of Canada to the course reform of Tibetan elementary education in China. Journal of Research on Education for Ethnic Minorities, 17(3), 77-80.

Liu, H. \& Sun, Z. (2006). Consideration of the distance education in rural primary and secondary schools from the perspective of effectiveness. Audio-Visual Education in China, 233(6), 38-41.

Liu, J. \& Zhang, W. (2008). Using ICT facilitated learning tools to develop teaching and research in rural basic education. Information Technology and Chinese Education, 14, 79.

Ma, X. \& Liang, G. (2008). The application of ICT in rural middle school instruction. Information Technology and Chinese Education, 12, 9-11.

Miao, F. (2005). Suggestions on applying the three distance education models to rural schooling. Information Technology Education for Primary and Secondary Schools, 8, 1316.

Moon, B. \& Robinson, B. (2003). Open and distance learning for initial teacher training. In B. Robinson \& C. Latchem (Eds.), Teacher education through open and distance learning (pp. 72-90). London: RoutledgeFalmer.

Ou Q. (2008). Applying constructivism to the application of three models of DEPRS. Popular Technology, 8, 191-192.

Peng, Su. (2007). On the application of the distance learning approaches in secondary education in Dangzhai Middle School of Zhangye County: A study case of the delivery model three. Unpublished master’s thesis, Northwest Normal University, Lanzhou, China.

Perraton, H. (2000). Open and distance learning in the developing world. London \& New York: Routledge.

Rabbi F \& Arefin, A. (2006). E-learning using wireless ad-hoc network to support people of rural areas. Communication Technology, ICCT appos, November: (27-30), 1-4. 
Robinson, B. (2008). Using distance education and ICT to improve access, equity and the quality in rural teachers' professional development in western China. International Review of Research in Open and Distance Learning, 9(1), 1-16.

Siaciwena, R. \& Lubinda, F. (2008). The role of open and distance learning in the implementation of the right to education in Zambia. International Review of Research in Page | 18 Open and Distance Learning, 9(1), 1-14.

Sujatha, K. (2002). Distance education at secondary level in India: the National Open School. UNESCO: International Institute for Educational Planning.

Sun, Y. \& Zhao, L. (2004). Current situation and strategies of developing distance education in the west minority nationality regions in the intellectual economics age. Journal of Radio \& TV University, 2, 111-114.

Wang, R. (2004). Education take-off in the west relying on the development of distance education. Journal of UESYC, 6(4), 105-108.

Wang, T. (2004). Present situation and development of rural basic education in northwest China. Distance Education in China, 3(32). 64-67.

Wang, Z. (2005, November). Reflection on the progress in Distance Education Project of Rural Primary and Secondary Schools. Paper presented at the Expert Forum on ChinaJapan Education Technology Studies and Development.

Wen, J. (2003, October 30). Speech at the national rural education work conference. China Education Paper.

Wolff, L, Castro, C, Navarro, J. C., \& Garcia, N. Television for secondary education: Experience of Mexico and Brazil. Technologies for Education, Retrieved January, 2009, from http://www.ictinedtoolkitorg/usere/library/tech

Wu, M. \& Yang, S. (2005). Research on the present situation of rural basic education in Xinjiang Minority Nationality Region during western development. Journal of Urumqi Adult Education Institute, 13(2), 11-13, 41.

Xie, W. (2007). Preliminary study of the DVD application in DEPRS. Information Technology Education for Primary and Secondary Schools, 10, 50-51, 66.

Yang, X. \& Han, W. (2007). An analysis of the applied benefits of DEPRS in west China. Education Information of China, 1, 20-22.

Yang, X. \& Jia, C. (2007). Cost analysis of the DEPRS in the primary and secondary education of rural western China. Basic Education, 1, 55-58. 
Yang, X. \& Jia, W. (2007). On the sustainable development of DEPRS in the western rural regions. Distance Education, 2, 46-50.

Yang, X. \& Sun, X. (2007). A tentative study of the cost sharing and compensation model of the DEPRS. Basic Education, 4, 56-59.

Yang, X., Sun, X., \& Ding, C. (2007). Cost and benefit analysis of modern long distance education of rural primary and middle schools in Gansu province. Journal of Gansu Lianhe University (Social Sciences), 23(6). 95-99.

Yang, Z. \& Yuan, B. (2006). The problems in the distance educational training program for primary and secondary teachers in poor rural areas as well as tentative solutions. Studies in Modern Distance Education, 5, 24-27.

$\mathrm{Yu}, \mathrm{S}$. (2005). Several directions of the continuing development of the rural distance education. Information Technology Education for Primary and Secondary Schools, 8, 912.

Yu, S. Q. \& Wang, M. J. (2006). Modern distance education project for the rural schools of China: Recent development and problems. Journal of Computer Assisted Learning, 22(4), 273-283.

Zhang, H. (2002). Modern distance education as the most feasible means of education development in the western minority regions. Journal of Lanzhou Commercial College, 18(4), 101-103.

Zhang, R. (2003). A new perspective on distance education in China: Teachers' training through distance education. Central Radio \& TV University, 1, 117-122.

Zhang, W \& Shi, T. (2008). Analysis of and search for solutions for a common phenomenon in distance learning tools' application in classroom instruction: 'The predilection of open course.’ Modern Educational Technology, 8, 78-81.

Zhao, H. (2005). Establishment of county oriented quality assurance system to achieve the sustainable development of the rural distance education. Unpublished master's thesis, Northwest Normal University, Lanzhou, China.

Zhao, J. (2005). Promoting rural teachers' professional development by means of distance learning resources. Unpublished master's thesis, Northwestern Normal University, Lanzhou, China.

Zhao, J., Hao, X. \& Banerjee, I. (2006). The diffusion of the internet and rural 
development, Convergence: The International Journal of Research into New Media Technologies 12(3), 293-305.

Zhuang, W. \& Lai, Y. (2002). The current situation and countermeasure in minority nationality region-case study of Yunnan, Guizhou \& Sichuan Provinces. Journal of Southwest University of Nationalities, May, 21-31.

Zibo Municipal Education Information Center. (2005, August) Introduction to the distance education project for rural schools. Retrieved January, 2009, from http://www.zbedu.net

\section{Endnotes}

${ }^{\mathrm{i}}$ According to the China Internet Information Center, the number of Internet users in China reached 137 million in 2007. However, the Centre did not provide a breakdown of the percentage of rural users. See J. Baggaley \& T. Belawati, (Eds.) (2007) Distance Education in Asia: I. Past and Present (Lahore: VUP) p. 45.

ii Between 1997 and 2005, several educational projects were carried on in China's underdeveloped areas, including the Project for Thousand Schools of Modern Educational Technology Experiment, Internet Development for Schools, Modern Distance Education Project for Western Primary and Secondary Schools, Internet Classroom and Information Station for Western Primary and Secondary Schools, National Teachers' Education Internet Program, Preparing for Tomorrow's Female Teachers, ChinaEurope Joint Program for Developing Basic Education in Gansu Province, China-Europe 403 Distance Education Program, Multi-Media Teaching Materials for Teachers' ICT Training, Program for Strengthening the Basic Education in Western China, Program for Study with Mutual Help (Yang \& Yuan, 2006, 24; Zhao, H. 2005, pp. 2-11).

iii The investment ratio between the central government and local governments varies according to the uneven development of different regions. In the rapidly developing east China, local governments take full responsibility for the cost; in Central China, local governments are responsible for two-thirds of the capital investment, while central government contributes one-third of the total cost. In the west, two-thirds of the capital outlay is provided by the central government, and the local governments only take care of the remaining one-third of the total cost (Liu \& Sun, 2006), p. 39.

${ }^{\text {iv }}$ For the programs implemented in Gansu Province, see Note 2.

${ }^{\mathrm{v}}$ The tuition of a number of college students of rural background in China are paid by their home county on the condition of their returning to the countryside after graduation.

${ }^{v i}$ By the end of 2005, when DEPRS would have been completed in Hubei, the first delivery model was to have been installed in 3,937 elemental schools (grade one to three), and the second delivery model was to have been implemented in 12,147 intermediate schools (grade one to six). In 2004 the Education Channel of Hubei TV began to broadcast, providing learning resources for rural schools simultaneously with the Central Television Station (Fang \& Shao, 2007), p. 35. 
